\title{
OUTCOME OF PCNL IN PROXIMAL URETERIC STONE: A COMPARATIVE STUDY WITH LAPAROSCOPIC RETRIEVAL
}

\author{
TANVIR AHMED ${ }^{1}$, MD HUMAYUN KABIR ${ }^{2}$, MD KHAIRUZZAMAN ${ }^{3}$, MD MONIRUL AHSAN $^{4}$, MIRANA \\ JAHAN $^{5}$, MD SAYEDUL ISLAM 6 \\ ${ }^{1}$ Department of Urology, Manikganj Medical College, ${ }^{2}$ Department of Urology Patuakhali Medical College, ${ }^{3}$ Department \\ of Urolgy Shaheed Tajuddin Ahmed Medical College, ${ }^{4}$ Department of Surgery Patuakhali Medical College, ${ }^{5}$ Department \\ of GynaeVictoria Hospital, Narayanganj.., ${ }^{6}$ Assoc. Prof. Dept of Urology, BSMMU.
}

\begin{abstract}
A hundred-percent stone clearance was achieved in a hospital based prospective clinical trial in which 60 cases of upper ureteric stone were selected by purposive sampling for percutaneous nephroureterolithotomy \& Laparoscopic ureterolithotomy between December 2012 and June 2014 in BSMMU. The mean age of the patients was 40.53 11.71 (19-61) and 41.23 \pm 10.76 (20-59) years old in PCNUL and LUL groups, respec-tively. The mean stone size in PCNUL group was 1.88 $\pm 0.39(1.06-2.45) \mathrm{cm}$ and in LUL group was 1.97 \pm 0.42 $(1.20-2.60) \mathrm{cm}$. The duration of the operations were $94.13 \pm 17.34(75-140)$ minutes, and $121.43 \pm 19.91(90-167)$ minutes $(P=0.001)$; and the average hospital stay days were $3.73 \pm 1.20(3-8)$ and $4.80 \pm 1.71(3-9)$ days $(P=0.017)$ in groups PCNUL and LUL, accordingly. The mean $\mathrm{Hb}$ decrease in PCNUL group was $1.16 \pm 0.35 \mathrm{mg} / \mathrm{dL}$ and in LUL group was $0.77 \pm 0.31 \mathrm{mg} / \mathrm{dL}(P=<0.001)$. No statistically significant differences in terms of fever and post operative prolon-ged urinary leakage were detected in both groups. Therefore the compared outcome is better in percutaneous nephroureterolithotomy group although stone clearance rate was same in percutaneous nephroureterolithotomy \& laparoscopic ureterolithotromy patients.
\end{abstract}

Key words: Percutaneous nephroureterolithotomy, Laparoscopic ureterolithotomy, Extracorporeal shock-wave lithotripsy

Bangladesh J. Urol. 2017; 20(2): 25-30

\section{Introduction:}

The treatment of upper urinary tract calculi has been revolutionized by the advent and development of percutaneous nephrolithotomy (PCNL) and extracorporeal shock wave lithotripsy (ESWL). The main advantage of PCNL is the higher success rate for larger stones as it is not dependent on the stone burden or composition like ESWL ${ }^{1-3}$. Until the 1980s, most ureteric calculi that required treatment were managed by open surgical ureterolithotomy or endoscopic basket extraction. The latter was the only endoscopic option but was appropriate only for small calculi in the distal third of the ureter. Laparoscopic surgery has added a further endoscopic minimally invasive option in urology.

Correspondences: Dr. Tanvir Ahmed, Assistant Professor of Urology, Manikganj Medical College, Manikganj, Bangladesh. E-mail: tanvirk53@yahoo.com.
Since the description of laparoscopic lymphadenectomy ${ }^{4}$ and laparoscopic nephrectomy ${ }^{5}$, the role of laparoscopy in urology has expanded enormously. A number of different ureteric procedures have been performed including nephro-ureterectomy ${ }^{5}$, ureterolysis $^{6}$ and ureteric resection and repair ${ }^{7}$. Wickham et al. were the first to describe the attempted removal of a ureteric calculus using the laparoscope ${ }^{8}$. Since then there have been only isolated reports of laparoscopic ureterolithotomy ${ }^{9-13}$.

In some medical centres with access advanced endourological equipment, open stone surgery is obsolete. However, some large ureteric stones pose a significant challenge for modern endourological techniques, often requiring several endoscopic procedures as well as SWL. Multiple procedures and prolonged periods with indwelling stents are not only 
expensive but also a burden to patients in terms of time off work and persistent pain. Since laparoscopic surgery has become widely adopted, nearly every operation has been reported via the laparoscopic approach, including laparoscopic ureterolithotomy. Gaur et al. have reported the largest series to date, all of which were performed extraperitoneally ${ }^{14}$.

In the light of recent development of various modalities of treatment of upper ureteric stones this study has been designed to compare the results of treatment of proximal ureteric stone by percutaneous nephroureterolithotomy and laparoscopic retrieval.

\section{Methods:}

In this Hospital based prospective clinical trial, 60 cases of upper ureteric stone were selected by purposive sampling for percutaneous nephroureterolithotomy \& Laparoscopic ureterolithotomy between December 2012 and June 2014. Purpose of the study was to compare the effectiveness and safety of PCNUL and Laparoscopic retrieval in patients having proximal ureteric stone.

\section{Techniques of the procedures:}

PCNUL : After asepsis and draping, under fluoroscopic or ultrasonographic guidance puncture of appropriate calyx was made with a translumber angioplasty needle. The needle was removed after insertion of a floppy tip J guide wire. Then the tract was dilated over the guidewire up to 28 to $30 \mathrm{Fr}$ by using dilators and an Amplatz sheath was introduced. Then nephroscope was placed through the sheath. Smaller stones were removed using forceps or a basket but larger stones were fragmented prior to extraction. At the end of procedure a nephrostomy tube was left within the tract and D-J stent was kept in ureter ${ }^{15,16}$.

LUL: After antiseptic skin preparation 3 ports/4ports [1 port was $5 \mathrm{~mm}$ and other 2 were $10 \mathrm{~mm}$ ] will be made in the abdomen. After mobilization of the colon medially ureter was be identified and through the guidance of the ureter proximal ureter was be reached. Then stone was identified to see the bulging in ureter. Then laparoscopic incision was be made on the ureter just over the stone and stone was be retrieved by stone grasper. A double$J$ stent was inserted to the ureter over a guidewire through suction canula after flushing the ureter proximally and distally ${ }^{13,14}$.

\section{Results:}

Among 30 patients of percutaneous nephrolithotomy group, age range were 19.00 to 61.00 years where mean age was $40.53 \pm 11.71$ and other 30 patients of laparoscopic ureterolithotomy group, age range were 20.00 to 59.00 years and mean age was $41.23 \pm 10.76$. Mean age difference of both groups was not statically significant $(P$-value $=0.801)$.

The male and female ratio in percutaneous nephroureterolithotomy group was 1: 0.30 and in laparoscopic ureterolithotomy group it was 1: 0.43.

Regarding clinical \& radiological characteristics of cases among 30 patients of PCNUL group ,0(0\%) patients had previous history of URS \& ICPL , 5(16.7\%) patients had previous history of ESWL \& $7(23.3 \%)$ patients had impacted stone in their upper ureter. 16(53.3\%) patients had right sided \& $14(46.7 \%)$ patients had left sided stone respectively in PNL group. PCNUL group also had $5(16.7 \%), 9(30 \%) \& 16(53.3 \%)$ patients who radiologically presented with mild, moderate \& severe hydronephrosis consecutively. Mean stone diameter of PCNUL group was $1.88 \pm 0.39 \mathrm{~cm}$ with the range of 1.06 to $2.45 \mathrm{~cm}$. Other 30 patients of LUL group had following features. $3(10 \%)$ of them had previous history of URS \& ICPL (P-value $=0.083)$ and other $3(10 \%)$ of them had previous history of $E S W L(P$-value $=0.489$ ). Among 30 LUL patients, $12(40 \%)$ patients had impacted stone in upper ureter $(P$-value $=0.202), 18(60 \%)$ patients had right sided stone $(P$-value $=0.625) \& 12(40 \%)$ patients had left sided stone( $P$-value $=0.625) .3(10 \%), 13(43.3 \%) \&$ $14(46.7 \%)$ patients had mild, moderate \& severe hydronephrosis respectively \& that were proven radiologically in LUL group ( $P$-value $=0.161,0.293 \&$ 0.601 respectively). This group had mean stone diameter of $1.97 \pm 0.42 \mathrm{~cm}$ with the range of 1.20 to $2.60 \mathrm{~cm}(P-$ value $=0.425$ ).

Operation time for PCNUL was calculated during beginning of percutaneous puncture and laparoscopy was calculated from beginning of placement of ports. Mean operation time of PCNUL patients was $94.13 \pm$ 17.34 minutes where the range was 75.00 to 140.00 minutes.

Table-I Operation time of PCNUL \& LUL groups $(n=60)$

\begin{tabular}{lccc}
\hline Groups & $\begin{array}{c}\text { Operation time Operation time } \\
\text { (minutes) } \\
\text { Range }\end{array}$ & $\begin{array}{c}P \\
\text { (minutes) } \\
\text { Mean } \pm S D\end{array}$ & value \\
\hline PCNUL & $(75.00-140.00)$ & $94.13 \pm 17.34<0.001$ \\
Group $(n=30)$ & & \\
LUL & $(90.00-167.00) 121.43 \pm 19.91$ & \\
Group ( $n=30)$ & & \\
\hline
\end{tabular}

Paired t- test, PCNUL-Percutaneous Nephroureterolithotomy, LUL- Laparoscopic Ureterolithotomy 
Mean operation time of LUL patients was $121.43 \pm 19.91$ minutes and in these cases range of operative time was 90.00 to 167.00 minutes. Paired sample t-test revealed significant difference of operative time between these two groups and $\mathrm{P}$-value was 0.001 .

Regarding post operative fever, $2(6.7 \%)$ \& 1 (3.3\%) patients of PCNUL \& LUL groups respectively had post operative fever and the difference between these two groups was not significant and was proven by t-test where P-value was 0.573 . Among 30 PCNUL patients none $(0)$ had prolonged urine leakage and only $2(6.7 \%)$ patients of LUL group had prolonged urine leakage and the difference of this complication in these two groups was also not significant where P-value was 0.161 . (Table-II).

Table-II Post operative complications of PCNUL \& LUL groups $(n=60)$

\begin{tabular}{lccc}
\hline Post operative & PCNUL & LUL & P \\
complications & $\begin{array}{c}\text { Group } \\
(n=30)\end{array}$ & $\begin{array}{c}\text { Group } \\
(n=30)\end{array}$ & value \\
\hline Post operative fever & $2(6.7 \%)$ & $1(3.3 \%)$ & 0.573 \\
Post operative prolonged & $0(0 \%)$ & $2(6.7 \%)$ & 0.161 \\
urine leakage & & & \\
\hline
\end{tabular}

Paired t- test

Mean post operative haemoglobin deficit in PCNUL group was $1.16 \pm 0.35$ and in LUL group was $0.77 \pm 0.31$. Paired sample t-test revealed significant difference of the deficit and $P$-value was 0.001.Among 30 PCNUL patients, 2(6.7\%) patients require blood transfusion in post operative period and among 30 LUL patients, 1(3.3\%) patients needed post operative blood transfusion, the difference of which is not significant and $P$-value was 0.573. Mean post operative pethidine requirement in PCNUL Group \& LUL Group were $85.83 \pm 21.21 \mathrm{mg} \& 83.83 \pm 17.79 \mathrm{mg}$ respectively. Dose range of pethidine in PCNUL group was 50 to $130 \mathrm{mg}$ and in LUL group was 60 to 130 $\mathrm{mg}$. The difference of pethidine requirement was not significant and paired t-test revealed P-value of 0.523 . ( Table-III )
Table-III Other post operative parameters of PCNUL \& LUL groups $(n=60)$

\begin{tabular}{lccc}
\hline $\begin{array}{l}\text { Other post operative } \\
\text { parameters }\end{array}$ & $\begin{array}{c}\text { PCNUL } \\
\text { Group } \\
(\mathrm{n}=30)\end{array}$ & $\begin{array}{c}\text { LUL } \\
\text { Group } \\
(\mathrm{n}=30)\end{array}$ & $\begin{array}{c}\mathrm{P} \\
\text { value }\end{array}$ \\
\hline $\begin{array}{l}\text { Post operative haemoglobin } \\
\text { deficit (mg/dl) (Mean } \pm \text { SD) }\end{array}$ & $2(6.7 \%)$ & $1(3.3 \%)$ & 0.573 \\
$\begin{array}{l}\text { Need for blood transfusion } \\
\text { in post operative period }\end{array}$ & $0.77 \pm 0.31$ & $<0.001$ \\
$\begin{array}{l}\text { Post operative pethidine } \\
\text { requirement (mg) } \\
\text { (Mean } \pm S D) \text { (Range) }\end{array}$ & $85.83 \pm 21.2183 .83 \pm 17.79$ & 0.523 \\
\hline
\end{tabular}

Mean hospital stays of PCNUL patients was $3.73 \pm 1.20$ days and range of stays was 3.00 to 8.00 days. Mean hospital stays of LUL Group was $4.80 \pm 1.71$ days and range of stays was 3.00 to 9.00 days. The difference of hospital stays of these two groups was significant and P-value was 0.017. (Table-IV)

Table-IV Hospital stays of PCNUL \& LUL groups $(n=60)$

\begin{tabular}{lccc}
\hline Groups & $\begin{array}{c}\text { Hospital stays } \\
\text { Days } \\
\text { Range }\end{array}$ & $\begin{array}{c}\text { Hospital stays } \\
\text { Days } \\
\text { Mean } \pm \text { SD }\end{array}$ & $\begin{array}{c}P \\
\text { value }\end{array}$ \\
\hline PCNUL & $(3.00-8.00)$ & $3.73 \pm 1.20$ & 0.017 \\
Group (n=30) & & & \\
LUL & $(3.00-9.00)$ & $4.80 \pm 1.71$ & \\
Group (n=60) & & & \\
\hline
\end{tabular}

\section{Paired t- test}

Regarding stone free rate, among 30 patients of PCNUL group, 30(100.0\%) patients became stone free at the end of the procedure. Among 30 patients of LUL group, $30(100.0 \%)$ patients became stone free at the end of the procedure. The difference of stone free status between these two groups was not significant and $\mathrm{P}$-value was 1.00. (Table-V)

Table-V Stone free status of PCNUL \& LUL groups $(n=60)$

\begin{tabular}{lccr}
\hline Groups & $\begin{array}{l}\text { Stone free } \\
\text { status No. }\end{array}$ & Percentage & P value \\
\hline $\begin{array}{l}\text { PCNUL Group } \\
(n=30)\end{array}$ & 30 & 100.0 & \\
LUL Group $(n=30)$ & 30 & 100.0 & 1.00 \\
\hline
\end{tabular}

Paired t- test 


\section{Discussion:}

In this study, age range of percutaneous nephroureterolithotomy group was 19.00 to 61.00 years where mean age was $40.53 \pm 11.71$ years and age range of laparoscopic ureterolithotomy group was 20.00 to 59.00 years where mean age was $41.23 \pm 10.76$ years. Mean age difference of both groups was not statically significant $(P$-value $=0.801)$. Almost comparable result was found in the study done by Karami et al. where mean age \& age range of percutaneous nephrolithotomy group \& laparoscopic ureterolithotomy group were 39.4 (16-63) years \& 35.2 (18-57) years respectively $(P-$ value $=0.21)^{17}$. Male patients were predominant than female patients in each group. In percutaneous nephroureterolithotomy group $76.7 \%$ patients were males and in laparoscopic ureterolithotomy group $70 \%$ patients were male ( $P$-value $=0.625)$.

Clinical and radiological characteristics of patients had been recorded. Among 30 percutaneous nephroureterolithotomy patients $0(0 \%)$ and $5(16.7 \%)$ patients had previous history of URS with ICPL \& ESWL respectively. On the other hand among 30 laparoscopic ureterolithotomy patients $3(10 \%)$ and other $3(10 \%)$ had previous history of URS with ICPL \& ESWL respectively ( $P$-value $=0.083 \& 0.489$ respectively). Karami's report showed $8(20 \%)$ and $4(10 \%)$ patients had previous history of ESWL in percutaneous nephroureterolithotomy \& laparoscopic ureterolithotomy groups respectively $(\mathrm{P}$ value $=0.35$ ) and no patients had previous history of URS with ICPL in each group ${ }^{17}$.

Among percutaneous nephroureterolithotomy patients, $5(16.7 \%)$ patients had mild, $9(30 \%)$ patients had moderate and $16(53.3 \%)$ patients had severe hydronephrosis, whereas in laparoscopic ureterolithotomy group $3(10 \%)$ patients had mild, $13(43.3 \%)$ patients had moderate \& $14(46.7 \%)$ patients had severe hydronephrosis( $P$-value $=0.161,0.293 \&$ 0.601 respectively). Hydronephrosis status found by Karami et al was almos nearer to the present study where $12.5 \%, 30 \% \& 57.5 \%$ of percutaneous nephroureterolithotomy patients had mild, moderate \& severe hydronephrosis respectively and $15 \%, 37.5 \%$ \& $47.5 \%$ laparoscopic ureterolithotomy patients had mild, moderate \& severe hydronephrosis consecutively( $P$ value $=0.67)^{17}$. Srivatava et al divided their patients into two groups where $57.44 \%$ patients comprised mild hydronephrosis \& $42.55 \%$ patients comprised moderate to severe hydronephrosis in ESWL group \& 100\% patients of percutaneous nephroureterolithotomy group had moderate to severe hydronephrosis ${ }^{18}$.
In the present study, mean stone diameter of percutaneous nephroureterolithotomy group was $1.88 \pm 0.39 \mathrm{~cm}$ with the range of $1.06 \mathrm{~cm}$ to $2.45 \mathrm{~cm}$ and in laparoscopic ureterolithotomy patients it was $1.97 \pm 0.42 \mathrm{~cm}$ with the range of $1.20 \mathrm{~cm}$ to $2.60 \mathrm{~cm}(P-$ value $=0.425)$.In Karami's report mean stone diameter of percutaneous nephroureterolithotomy group was 1.42 $\mathrm{cm}$ with the range of $1.0 \mathrm{~cm}$ to $2.5 \mathrm{~cm}$ and in laparoscopic ureterolithotomy patients it was $1.35 \mathrm{~cm}$ with the range of $1.0 \mathrm{~cm}$ to $2.8 \mathrm{~cm}$ and the report was almost similar to the present study $(P \text {-value }=0.56)^{17}$.

Mean operative time of percutaneous nephroureterolithotomy patients was $94.13 \pm 17.34$ minutes with the range of 75.00 minutes to 140.00 minutes and in laparoscopic ureterolithotromy patients it was $121.43 \pm$ 19.91 minutes with the range of 90.00 minutes to 167.00 minutes, the difference between was statistically significant $(P$-value $=0.001)$. Karami et al reported mean operative time $\&$ their range in percutaneous nephroureterolithotomy \& laparoscopic ureterolithotromy groups were 54.35 minutes ( $50-82$ minutes) \& 82.15 minutes (73-180 minutes) respectively, where the difference between was also statistically significant like the present study ( $P$-value $=0.001)^{17}$. Other study revealed almost similar operative time in laparoscopic ureterolithotromy patients.

Post operative complications were also recorded in this study. In the present series, post operative complications like post operative fever, post operative prolonged urine leakage between percutaneous nephroureterolithotomy \& laparoscopic ureterolithotomy groups were compared and found not statistically significant ( post operative fever in $2(6.7 \%)$ patients vs. $1(3.3 \%)$, P-value $=0.573$, post operative prolonged urine leakage in $0(0 \%)$ patients vs. $2(6.7 \%)$ patients , P-value $=0.161)$. Study reported by Karami et al revealed, differences of these two post operative complications were also not significant between percutaneous nephroureterolithotomy \& laparoscopic ureterolithotomy groups (post operative fever in 5(12.5\%) patients vs. $4(10 \%)$, P-value $=0.99$, post operative prolonged urine leakage in $0(0 \%)$ patients vs. $1(2.5 \%)$ patients, P-value $=0.24){ }^{17}$. Harewood et al reported post operative urine leakage in their $5(55.55 \%)$ of 9 laparoscopic ureterolithotomy patients which ranged from 1 to 3 days but not prolonged ${ }^{19}$.

The average haemoglobin decrease in the first post operative day in percutaneous nephroureterolithotomy group was significantly higher than laparoscopic ureterolithotomy patients $(1.16 \pm 0.35 \mathrm{mg} / \mathrm{dl}$ vs . 
$0.77 \pm 0.31 \mathrm{mg} / \mathrm{dl}, \mathrm{P}$ value $=0.001)$. Karami reported mean haemoglobin deficit of $0.9 \mathrm{mg} / \mathrm{dl}$ in percutaneous nephroureterolithotomy group \& $0.4 \mathrm{mg} / \mathrm{dl}$ in laparoscopic ureterolithotomy group. Here in percutaneous nephroureterolithotomy group haemoglobin deficit is also significantly higher than laparoscopic ureterolithotomy group $(P \text {-value }=0.001)^{17}$. In the present study $2(6.7 \%)$ percutaneous nephroureterolithotomy patients \& $1(3.3 \%)$ laparoscopic ureterolithotomy patients required blood transfusion in post operative period, the difference of which was not statistically significant $(P$-value $=0.573$ ). Karami et al reported only $3(7.5 \%)$ of percutaneous nephroureterolithotomy patients and none of laparoscopic ureterolithotomy patients required blood transfusions in post operative period the difference of which was also not statistically significant ( $P$-value $=0.24)^{17}$.

Need for mean post operative parenteral pethedine requirement and its range in percutaneous nephroureterolithotomy \& laparoscopic ureterolithotomy groups were $85.83 \pm 21.21 \mathrm{mg}(50 \mathrm{mg}$ to $130 \mathrm{mg})$ \& $83.83 \pm 17.79(60 \mathrm{mg}$ to $130 \mathrm{mg}$ ) respectively. Here the difference of pethidine requirement was not statistically significant $(P$ value $=0.523$ ). Karami reported almost similar result where mean post operative parenteral pethedine requirement and its range in percutaneous nephroureterolithotomy \& laparoscopic ureterolithotomy groups were $80 \mathrm{mg}$ (50 mg to $200 \mathrm{mg}$ ) \& $77.5 \mathrm{mg} \mathrm{(50}$ $\mathrm{mg}$ to $150 \mathrm{mg}$ ) respectively the difference of which was also not statistically significant $(P$ value $=0.92){ }^{17}$. Harewood et al reported mean post operative parenteral pethedine requirement in their laparoscopic ureterolithotomy group was $272 \mathrm{mg}$ which was higher than present series ${ }^{19}$.

Mean hospital stay of percutaneous nephroureterolithotomy patients was $3.73 \pm 1.20$ days with the range of 3 to 8 days \& in laparoscopic ureterolithotromy group it was $4.80 \pm 1.71$ days with the range of 3 to 9 days, the result of which was statistically significant ( $\mathrm{P}$ Value $=0.017$ ). Karami's report was also statistically significant where mean hospital stay \& its range in percutaneous nephroureterolithotomy \& laparoscopic ureterolithotromy groups were 2.6 ( 2 to 5 ) days \& 3.5 (3 to 8 ) days respectively $(P \text {-value }=0.001)^{17}$. Goel et al reported almost similar days of hospital stay in their laparoscopic ureterolithotromy patients, the mean of which was 3.3 days with the range of 2 days to 14 days ${ }^{20}$.

In this study, stone clearance rate was $100.0 \%$ \& $100.0 \%$ respectively in percutaneous nephroureterolithotomy \& laparoscopic ureterolithotromy groups \& the difference between was not statistically significant $(P$ value $=1.00$ ). Karami et al reported $100 \%$ stone clearance in each group and here the difference between was also not statistically significant $(P \text {-value }=1.00)^{17}$. Srivastava et al reported $79.3 \%$ stone clearance rate in their percutaneous nephroureterolithotomy group ${ }^{18}$.

In the present series, there are some reports which show significant differences between percutaneous nephroureterolithotomy \& laparoscopic ureterolithotromy patients like mean opearation time; post operative haemoglobin deficit \& post operative hospital stays. Haemoglobin deficit was more in percutaneous nephrolithotomy group and on the other hand operation time \& hospital stays were more in laparoscopic ureterolithotromy patients. Carbon dioxide insufflations, placement of 3 ports \& handling of colon during laparoscopy also produced discomfort of the patients in post operative period. 2 of 30 laparoscopic ureterolithotromy patients were also suffered prolonged post operative urine leak whereas no percutaneous nephrolithotomy patient suffered prolonged post opetative urine leakage. Stone clearance rate was same in percutaneous nephrolithotomy \& laparoscopic ureterolithotromy patients.

Therefore, if the present study compare patient's outcome in these two groups it is seen that outcome is comparatively better in percutaneous nephrolithotomy group and is also evidenced by previous study 17 .

\section{Conclusion:}

It seems that the percutaneous nephroureteo-lithotomy has comparable results with laparoscopic ureterolitho-tomy for the treatment of the proximal ureteral stones with lower operation time and hospitalization period. Outcome of patients was comparatively better in percutaneous nephrolithotomy group.

\section{References}

1. May DJ, Chandhoke PS (1998). Efficacy and costeffectiveness of extracorporeal shock wave lithotripsy for solitary lower pole renal calculi. Journal of Urology; 159(1):24-7.

2. Netto NR Jr, Claro JF, Lemos GC, Cortado PL (1991). Renal calculi in lower pole calices: what is the best method of treatment? Journal of Urology, 146(3):721-3.

3. Tiselius HG, Ackermann D, Alken P, Buck C, Conort P, Gallucci M (2006). Guidelines on 
urolithiasis. http://www.uroweb.org/fileadmin/ userÙupload/Guidelines/18\%20Urolithiasis.pdf (accessed January 2013).

4. Schuessler WW. Vancaille TG, Reich H. Griffith DP (1991).Transperitoneal endosurgical lymphadenectomy in patients with localized prostate cancer. J Urol; 145: 988-91.

5. Clayman RV, Kavoussi LR, Figenshau RS, Chandhoke PS, Albala DM(1991) Laparoscopic nephroureterectomy: initial clinical case report. J Laparoendosc Surg;1: 343.

6. Kavoussi LR. Clayman RV, Brunt M, Soper NJ (1992). Laparoscopic ureterolysis. J Urol ; 147: 426-9.

7. Nezat C. Nezhat F, Green B (1992). Laparoscopic treatment of obstructed ureter due to endometriosis by resection and ureteroureterostomy: a case report. J Urol; 148: 865-8.

8. Wickham JEA (1979). The surgical treatment of renal lithiasis. In Wickham JEA. Urinary Calculous Disease. Edinburgh: Churchill Livingstone.

9. Raboy A, Ferzli GS. loffreda R, Albert PS (1992). Laparoscopic ureterolithotomy. Urology: 223- 5.

10. Gaur DD (1992). Laparoscopic operative retroperitoneoscopy: use of a new device. $J$ Urol ; 148: 1137-9.

11. Gaur DD, Agarwal DK. Purohit KC (1993). Retroperitoneal laparoscopic ureterolithotomy and renal biopsy. J Urol ;149: 408A Abstract no. 783.

12. Webb DR, Redgrave N, Chan Y, Harewood LM (1993). Extraperitoneal laparoscopy: early experience and evaluation. Aust NZ J Surg; 63: 554-7.

13. Wuernschimmel E, Lipsky H (1993). Laparoscopic treatment of an upper ureteral stone. $J$ Laparoendosc Surg; 3:301-307.

14. Gaur DD, Agarwal DK, Purohit KC, Darshane AS, Shah BC (1994). Retroperitoneal laparoscopic ureterolithotomy for mul- tiple upper mid ureteral calculi. J Urol ; 151: 1001-2.15. Lingeman JE, Coury TA, Newman DM (1987): Comparison of results and morbidity of percutaneous nephrostolithotomy and extracorporeal shock wave lithotripsy. J Urol; 138:485.

16. Preminger GM, Clayman RV, Hardeman SW (1985). Percutaneous nephrostolithotomy vs. open surgery for renal calculi. JAMA; 254:1054.

17. Preminger GM, Clayman RV, Hardeman SW (1985). Percutaneous nephrostolithotomy vs. open surgery for renal calculi. JAMA; 254:1054.

18. A. Shrivastav, R Ahlawat, A Kumar, R Kapoor and M Bhandari (1992). Management of impacted upper ureteric calculi: Results of lithotripsy and percutaneous litholapaxy. Br J Urol ; 70 :252-257.

19. L.M. HAREWOOD. D.R. WEBB and A.J. POPE (1994). Laparoscopic ureterolithotomy: the results of an initial series, and an evaluation of its role in the management of ureteric calculi. British Journal of Urology; 74:170-176.

20. A. Goel, A.K. Hemal (2001). Upper and mid-ureteric stones: a prospective unrandomized comparison of retroperitoneoscopic and open ureterolithotomy. BJU International ; 88: 679-682. 